\title{
ИНТЕРПРЕТАЦИИ ПРОИСХОДЯЩЕГО В ПАНДЕМИЮ COVID-19 И МИШЕНИ ПСИХОТЕРАПЕВТИЧЕСКОЙ РАБОТЫ С ЛЮДЬМИ, РАНЕЕ ОБРАЩАВШИМИСЯ К ПСИХИАТРУ
}

Ениколопов С.Н., Бойко О.М., Медведева Т.И., Воронцова О.Ю., Казьмина О.Ю. (Федеральное Государственное Бюджетное Научное Учреждение «Научный чентр психического здоровья», Москва, Россия), enikolopov@mail.ru

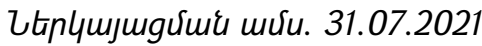

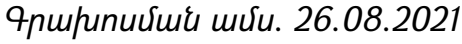

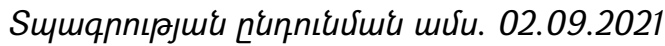

Люди, ранее обращавшиеся за психиатрической помощью, тяжелее переживают пандемию COVID-19 и чаще нуждаются в психотерапевтической поддержке. Одним из способов исследования состояние человека и его личностных особенностей является анализ интерпретаций происходящего. Цели работы: анализ особенностей интерпретации ситуации людьми, ранее обращавшимися за психиатрической помощью, выявление мишеней психотерапевтической помощи. Материалы и методы: проанализированы данные анонимного интернет-опроса (всего 659 ответов, из которых 152-от людей, обращавшихся ранее за психиатрической помощью). Опрос включал вопросы об уровне тревоги, депрессии, страха и свободный вопрос про отношение к ситуации пандемии. Результаты: у обращавшихся ранее за психиатрической помощью выше уровень тревоги, подавленности, ниже уровень успешного совладания со страхом, реже используются интерпретации по типу "теории заговора», выше встречаемость темы «про себя», негативного образа будущего и настоящего, лексики гнева. При этом отмечается более частое упоминание плюсов ситуации и реакции интереса. Выводы: у людей, обращавшихся за психиатрической помощью, отмечается выраженная амбивалентность отношения к ситуации, сосредоточенность на собственных переживаниях, фантазии о будущем негативного характера, что является мишенями психотерапевтической работы.

Ключевые слова: COVID-19, интерпретачия, психическая болезнь, nсихотерапия.

DOI: https://doi.org/10.46991/SBMP/2021.4.2.142

Пандемия COVID-19 создает высокий уровень стресса. Люди, обращавшиеся ранее за психиатрической помощью, острее реагируют на сложившуюся ситуацию и значимо чаще сообщают о потребности в психологической помощи [1]. Поэтому важно повышение осведомленности специалистов в области психического здоровья об особенностях их состояния. Сбор данных при помощи Интернета широко используется в пандемию COVID-19 для 
мониторинга ситуации и реакций на нее [7], выделения людей, особенно тяжело реагирующих на пандемию и разработки программ помощи им [5].

Состояние человека, его личностные особенности проявляются в том, как он интерпретирует реальность. Интерпретация ситуации - это результат психического процесса, который начинается с этапа восприятия и первичной оценки и продолжается в ходе последующей переработки информации. Именно интерпретация выражает взгляд человека на происходящее и содержит обоснование для его дальнейших действий по совладанию с ситуацией. Выявлена связь между характером интерпретаций происходящего в пандемию COVID-19 и соблюдением противоэпидемических мер [2]. Анализ интерпретаций происходящего дает возможность выделить мишени помощи людям, страдающим психическими заболеваниями, что способно сделать более эфффективной работу специалистов области психического здоровья, повысить качество оказываемой помощи.

Целью исследования был анализ особенностей интерпретации ситуации людьми, обращавшимися ранее за психиатрической помощью, и выявление мишеней психотерапевтической работы.

Материалы и методы. Материалом исследования стали данные, полученные в ходе анонимного интернет-опроса российской выборки с 20.03.2020 по 13.01.2021. Группа «обращавшихся ранее за психиатрической помощью» была выделена с помощью вопроса: «обращались ли Вы когданибудь к психиатру». Из полученных 659 ответов 152 человека сообщили, что обращались за психиатрической помощью, 506 человек составили группу сравнения. В опросе не уточнялся диагноз респондента, поэтому выделенная группа является нозологически разнородной. Опрос включал вопросы об уровне тревоги, депрессии, страха и свободный вопрос про отношение к ситуации пандемии. Ответ на свободный вопрос кодировался экспертамипсихологам, выделявшими его смысловое и аффрективное содержание. Кодировались темы, встречающиеся в ответе, например, тема будущего, тема «ощущения сопричастности», тема «забота о других» и т.д. Один ответ мог содержать в себе несколько тем и разное афрективное содержание, что указывалось при кодировке. Так, тема «Гнев» включала в себя широкий набор лексики: бешенство, бесит, бешусь, досада, исступление, злоба, злость, неудовольствие, остервенение, раздражение, свирепый, ярость, сгоряча, вспыльчивый, агрессия. Статистический анализ проводился в программе SPSS, для сравнения групп использовались критерии t-Стьюдента и Pearson ChiSquare. 
Результаты. Социодемографические характеристики выборки: всего приняло участие в исследовании 659 человек, группу сравнения составили 507, 152 отмечали, что обращались к психиатру. Всего в выборке 133 мужчины, 526 женщин. 87,2\% мужчин вошли в группу сравнения и 17,3\% - в группу обращавшихся ранее за психиатрической помощью. Из женщин, принявших участие в исследовании в группу сравнения вошли $75,5 \%$, в группу обращавшихся за психиатрической помощью - 24,59\%. Средний возраст в общем по выборке составил $41,7 \pm 11,8$, в группе сравнения $42,0 \pm 11,7$, в группе людей, обращавшихся за психиатрической помощью 40,5 $\pm 11,5$. Применение критерия Pearson Chi-Square $x^{2}(1)=3,13, p=.047$ указывает на статистически значимое преобладание женщин в группе обращавшихся за психиатрической помощью. Результаты статистической обработки $\mathrm{F}(1,88)=3,163, \mathrm{p}=.171$ указывают на отсутствие статистически значимых различий по возрасту между группами по возрасту. Использование критерия T-student демонстрирует наличие статистически значимых различий между группами. Группа респондентов, обращавшихся ранее за психиатрической помощью, переживает более сильную тревогу $(5,533 \pm 2,489$ по сравнению с 4,774 $\pm 2,590 \mathrm{p}=, 000)$, подавленность $(4,945 \pm 2,926$ по сравнению с 3,861 $22,988 p=, 000)$ и страхи за себя и других $(0,195 \pm 0,397$ по сравнению с 0,278 $\pm 0,448 p=, 007)$.

Таблица 1. Примеры выделенньх интерпретаций

\begin{tabular}{|c|c|}
\hline $\begin{array}{c}\text { Тема } \\
\text { интерпретации }\end{array}$ & \\
\hline $\begin{array}{l}\text { «Теория } \\
\text { заговора» }\end{array}$ & $\begin{array}{l}\text { В стране искусственно созданная паника, подогреваемая безграмотными } \\
\text { (или умышленно провокационными) действиями властей, запугиванием, } \\
\text { оскорблениями, хамским тоном заявлений чиновников }\end{array}$ \\
\hline «Про себя» & $\begin{array}{l}\text { Я думаю, что по большей части от меня ничего не зависит. Я отвечаю только } \\
\text { за себя и могу только соблюдать меры безопасности, которые мне доступны. }\end{array}$ \\
\hline Тема будущего & $\begin{array}{l}\text { Если это затянется, то будет тяжело. У меня, например, нет сбережений } \\
\text { (правда, и кредитов тоже нет) }\end{array}$ \\
\hline $\begin{array}{l}\text { Негативный образ } \\
\text { будущего }\end{array}$ & Конец близок \\
\hline $\begin{array}{l}\text { Взгляд на } \\
\text { ситуащию из } \\
\text { будущего }\end{array}$ & $\begin{array}{l}\text { Интересный опыт, который можно использовать в автобиографии или } \\
\text { художественной литературе }\end{array}$ \\
\hline Плюсы ситуации & $\begin{array}{l}\text { Лично мне ситуация с короновирусом в этом году пошла почти } \\
\text { исключительно на пользу. }\end{array}$ \\
\hline $\begin{array}{l}\text { Негативный } \\
\text { образ настоящего }\end{array}$ & $\begin{array}{l}\text { Вирус распространяется. Он особенно опасен для людей из группы риска, а } \\
\text { тажже грозит коллапсом системы здравоохранения. Карантин необходим. } \\
\text { Власти действуют запоздало и недостаточно последовательно. Мало } \\
\text { разъяснительной информации для населения, часть которого совершенно не } \\
\text { понимает смысла карантинньх мероприятий. }\end{array}$ \\
\hline
\end{tabular}


Таблица 2. Оценка различий интерпретаций между группами по критерию Pearson Chi-Square $+$

\begin{tabular}{|l|r|r|r|}
\hline & $\begin{array}{l}\text { Группа } \\
\text { сравнения } \\
(\mathrm{N}=507)\end{array}$ & $\begin{array}{l}\text { Обращались к } \\
\text { психиатру } \\
\text { (N=152) }\end{array}$ & $\begin{array}{l}\text { Pearson } \\
\text { Chi- } \\
\text { Square }\end{array}$ \\
\hline «Теория заговора» & $16,17 \%$ & $9,87 \%$ &, 033 \\
\hline «ро себя» & $13,21 \%$ & $20,39 \%$ &, 022 \\
\hline Тема будущего & $16,77 \%$ & $27,63 \%$ &, 003 \\
\hline Негативный образ будущего & $9,47 \%$ & $15,79 \%$ &, 028 \\
\hline Взгляд на ситуацию из будущего & $1,38 \%$ & $3,95 \%$ &, 046 \\
\hline Плюсы ситуации & $0,99 \%$ & $3,30 \%$ &, 042 \\
\hline Гнев & $2,17 \%$ & $5,92 \%$ &, 023 \\
\hline Негативный образ настоящего & $1,58 \%$ & $3,64 \%$ &, 041 \\
\hline Любопытство, интерес & $2,37 \%$ & $5,92 \%$ &, 029 \\
\hline
\end{tabular}

Выявились значимые различия в использованных интерпретациях у представителей разных групп. Так, в группе людей, обращавшихся ранее за психиатрической помощью, ниже процент использования в интерпретации текущей ситуации теорий заговора (9,87 \% по сравнению с 16,17\% при p=0,033) и выше процент встречаемости темы «про себя» $(20,39$ \% по сравнению с $13,21 \%$ при $\mathrm{p}=0,022)$, темы будущего $(27,63 \%$ по сравнению с 16,77 \% при $\mathrm{p}=0,003)$, негативного образа будущего (15,79\% по сравнению с 9, 47 \% при $\mathrm{p}=0,028)$, взгляда на ситуацию из будущего (3,95 \% по сравнению с 1,38 \% $\mathrm{p}=0,046)$, упоминания плюсов ситуации, негативного образа настоящего (3,64\% по сравнению с 1,58\% при $\mathrm{p}=0,041)$, а также таких эмоциональных реакций как гнев $(5,92 \%$ по сравнению с $2,17 \%$ при $p=0,023)$, любопытство/интерес (5,92 \% по сравнению с 2,37 \% при p=0,029).

Обсуждение результатов. Представляет интерес существенно меньший процент обращений к теориям заговора при интерпретации ситуации пандемии у группы респондентов, ранее обращавшихся к психиатру. Это может быть связано с тем, что такого рода интерпретации, при сохранной критичности к собственному психическому состоянию, могут маркироваться человеком как проявления болезни и из-за этого отвергаться. Одновременно с этим, само наличие опыта признания собственных убеждений не соответствующими действительности может приводить к настороженности в отношении своих выводов. При этом, специалист области психического здоровья начинает для пациента играть роль эксперта, к которому обращаются для уточнения правильности собственного понимания реальности. Другим объяснением может быть наличие успешного опыта получения психиатрической помощи, который помогает с доверием относиться к медицинской информации о COVID-19. Bсё 
это подтверждает важность хорошего контакта с врачом в социальной адаптации человека, страдающего психическим заболеванием [4].

В группе обращавшихся к психиатру чаще негативно оценивается настоящее, будущее, что может отражать субъективные переживания незащищенности, опасности и объясняться трудностями совладания с тревогой (показатель выше, чем в группе сравнения) и неопределенностью, которые возникают в ситуации пандемии или усиливаются ею. Негативная оценка настоящего и будущего становится способом преодоления неопределенности, который, ненадолго успокаивая, помогая не вовлекаться в новый цикл «надежда-разочарование», способен многократно усиливать депрессивные и фобические реакции. Вероятно, использование образа будущего в интерпретациях происходящего не способно в настоящий момент выступать как способ психологической защиты, так как сохраняется высокий уровень неопределенности, сложности долговременного планирования своей жизни. По всей видимости, уровень стресса, генерируемый ситуацией пандемии, для людей, ранее обращавшихся за психиатрической помощью, респондентов настолько высок, что инкапсулирует их в текущей психотравмирующей ситуации, лишая возможности вообразить хорошее будущее, то есть использовать одну из важных стратегий по совладанию со стрессом [6].

В практической работе это диктует необходимость помощи обращающимся в совладании с имеющимися эмоциональными реакциями на ситуацию, в аспекте снижения их интенсивности до переносимой. Это возможно при контейнировании переживаний, важными этапами которого являются поиск слов, отражающих чувства, захватывающие человека, выдвижение предположения о том, какое событие во внешней и внутренней жизни человека их вызвало. Одновременно с этим будут полезными когнитивные техники, помогающие интегрировать противоположные характеристики ситуации и направленные на преодоление негативной селективности внимания. Также полезными может быть применение арттерапевтических методов, помогающих человеку символизировать его переживания. Они применимы и к наблюдаемой амбивалентности в реакциях на ситуацию у людей, ранее обращавшихся за психиатрической помощью, которая выражается в противоречивости тем, присутствующих в интерпретациях: одновременно интерес, любопытство и акцентирование плюсов текущей ситуации, и гнев по отношению к ней, фобические, депрессивные и тревожные реакции.

Полученные результаты также показывают смещение фокуса внимания у людей, обращавшихся ранее за психиатрической помощью, в сторону фриксации на собственном состоянии, что может усиливать и закреплять тревожные, депрессивные и фобические реакции, а также усиливать 
переживание настоящего как негативного. Они значимо чаще пишут о себе, демонстрируя большую эгоцентричность позиции, чем в группе сравнения, кроме того, сообщают, что никак не могут повлиять на ситуацию. Оценка с позиции взгляда из будущего, также подчеркивает индивидуальный опыт преодоления без включения его в социальный контекст (автобиография) [3]. Это может указывать на необходимость в психотерапевтической и поддерживающей работе расширения поля внимания с включением в фрокус внимания аспектов ситуации, не относящихся лично к пациенту, и обсуждением его возможного вклада в её преодоление.

Таким образом, сравнительный анализ интерпретаций ситуации пандемии подтверждает наличие особенностей переживания пандемии людьми, обращавшимися ранее за психиатрической помощью.

Выводы. Анализ интерпретаций ситуации пандемии COVID-19 у людей, обращавшихся ранее к психиатру, показал наличие выраженной амбивалентности эмоциональных реакций, сосредоточенности на собственных переживаниях, более сильные тревожные, депрессивные и фобические реакции, а также такие негативные в долгосрочной перспективе компенсаторные стратегии по отношению к ситуации неопределенности как фантазии о будущем в негативного характера. Всё это должно учитываться специалистами в области психического здоровья и может являться мишенями работы при помощи обращающимся.

Ограничения работы. Не изучался вклад в состояние респондентов других экстремальных событий, произошедших в период пандемии. В связи с методологическими особенностями работы, есть ограничения при экстраполяции полученных результатов на общую выборку.

\section{Литература}

1. Бойко О.М., Медведева Т.И., Ениколопов С.Н., Воронцова О.Ю., Казьмина О.Ю. Психологическое состояние людей в период пандемии COVID-19 и мишени психологической работы [Online]. Психологические исследования. $2020 . \quad № 70 . \quad$ URL: http://psystudy.ru/index.php/num/2020v13n70/1731-boyko70.html.

2. Бойко О.М., Медведева Т.И., Ениколопов С.Н., Воронцова О.Ю. Соблюдение противоэпидемических мер и интерпретации происходящего во время пандемии COVID-19. Девиантология. 2020; 4 (2): 8-21. DOI: 10.32878/devi.20-4-02(7)-8-21

3. Ениколопов С.Н. Медведева Т.И., Воронцова О.Ю., Чудова Н.В., Кузнецова Ю.М., Пенкина М.Ю., Минин А.Н., Станкевич М.А., Смирнов И.В., Любавская А.А. Лингвистические характеристики 
текство психически больных и здоровых людей. Психологические исследования. 2018, Т11, №61, С. 1.

4. Нуллер Ю.Л., Михаленко И.Н. Афффективные психозы. Ленинград, «Медицина», 1988

5. Clay J.M., Parker M.O. Alcohol use and misuse during the COVID-19 pandemic: a potential public health crisis? // The Lancet Public Health. 2020. - Vol. 5. - N5. - P. e259. doi: 10.1016/S2468-2667(20)30088-8.

6. Sapolsky R. M. Why zebras don't get ulcers: a guide to stress, stress related diseases, and coping. - New York: W.H. Freeman, 1994. - xii, 368 p.

7. Xue J., Chen J., Hu R., Chen Ch., Zheng Ch., Su Y., Zhu T. Twitter Discussions and Emotions About the COVID-19 Pandemic: Machine Learning Approach J Med Internet Res 2020;22(11):e20550 DOI: 10.2196/20550.

\section{INTERPRETATIONS OF THE COVID-19 PANDEMIC AND THE TARGETS OF THE PSYCHOTHERAPY WITH PEOPLE, WHO PREVIOUSLY HAVE SOUGHT PSYCHIATRIC ASSISTANCE.}

Enikolopov S.N., Boyko O.M., Medvedeva T.I., Vorontsova O.Yu., Kazmina O.Yu. (Federal Stare Budgetary Scientific Institution "Mental Health Research Center", Moscow, Russia)

People, who previously have sought psychiatric assistance, are harder reacting to COVID-19 pandemic and they are needing psychotherapeutic help more often, then other people. An analysis of interpretation of the situation is one of the ways to research the human condition and personality traits.

Aims of this research involved analysis of interpretations of the situation by people, who previously have sought psychiatric assistance, and identification targets of psychotherapy to them.

Materials and methods: the date of an anonymous internet-survey analyzed (659 responses, that included 152 - from people, who previously have sought psychiatric assistance). The survey included the questions about the levels of anxiety, depression, fear and one open question about attitude to COVID-19 pandemic.

Results: People, who previously have sought psychiatric assistance, have higher levels of anxiety, depression, and lower levels of the effective coping with the fear, less used interpretation conspiracy theory's type, higher occurrence theme "about myself", negative vision of a present and a future, a vocabulary of an anger. They reported about bright sides of pandemic and more reaction of curiosity more often than other people. 
Conclusions: The targets of psychotherapy to the people, who previously have sought psychiatric assistance, are ambivalence in the attitudes towards pandemic, concentration themselves feelings, negative vision of the future.

Keywords: COVID-19, interpretation, psychical illness, psychotherapy. 